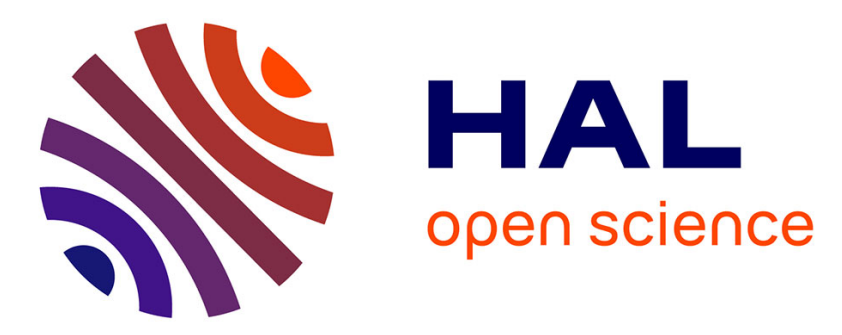

\title{
Demo: Unleashing the power of LED-to-camera communications for IoT devices
}

Alexis Duque, Razvan Stanica, Hervé Rivano, Adrien Desportes

\section{To cite this version:}

Alexis Duque, Razvan Stanica, Hervé Rivano, Adrien Desportes. Demo: Unleashing the power of LED-to-camera communications for IoT devices. Proceedings of the 3rd Workshop on Visible Light Communication Systems, Oct 2016, New York City, United States. 10.1145/2981548.3003712 . hal01819404

\section{HAL Id: hal-01819404 https://hal.inria.fr/hal-01819404}

Submitted on 20 Jun 2018

HAL is a multi-disciplinary open access archive for the deposit and dissemination of scientific research documents, whether they are published or not. The documents may come from teaching and research institutions in France or abroad, or from public or private research centers.
L'archive ouverte pluridisciplinaire HAL, est destinée au dépôt et à la diffusion de documents scientifiques de niveau recherche, publiés ou non, émanant des établissements d'enseignement et de recherche français ou étrangers, des laboratoires publics ou privés. 


\section{Demo: Unleashing the power of LED-to-camera communications for loT devices}

\author{
Alexis Duque \\ Rtone, Lyon, France \\ Univ Lyon, INSA Lyon, Inria, CITI \\ F-69621, Villeurbanne, France \\ alexis.duque@insa-lyon.fr \\ Herve Rivano \\ Univ Lyon, Inria, INSA Lyon, CITI \\ F-69621, Villeurbanne, France
}

\author{
Razvan Stanica \\ Univ Lyon, INSA Lyon, Inria, CITI \\ F-69621, Villeurbanne, France
}

Adrien Desportes
Rtone, Lyon, France

\begin{abstract}
In this demonstration, we propose a line of sight LED-tocamera communication system based on an ordinary LED and a smartphone. We designed a cheap temperature sensor prototype as a proof of concept of a near communication framework for the Internet of Things. To illustrate a typical use case, we have programmed the micro-controller to broadcast the ambient temperature value through the LED. The user, with his smartphone and our Android application can then retrieve the transmitted information, aiming the board with the camera.
\end{abstract}

\section{INTRODUCTION}

With the rise of the Internet of Things (IoT), consumer electronics products, which yesterday were single function, tend to be smarter and connected to the user, through his smartphone. However, providing wireless connectivity with Bluetooth Low Energy (BLE) or WiFi means adding an extra radio chip, increasing the object size and price.

This kind of hardware modification is not without impact for the manufacturers: even if the radio chip cost is negligible for a single unit, it may become huge when millions of product are sold. Also, the health impact of radio waves is not yet fully understood.

Besides, many of these products already have a microcontroller unit (MCU) and light-emitting diodes (LED), which are the only requirement to enable visible light communication. To further reduce the cost of the system, an onthe-shelf smartphone can receive information through visible light thanks to its camera.

This demonstration aims to illustrate such scenario, which targets short-range (tens of centimeters) and low throughput (hundreds of bits per second) communications for the IoT.

\section{DEMONSTRATION DESCRIPTION}

\subsection{Emitter}

We designed a 40x20mm printed circuit board (PCB) that supports a surface mounted LED, a MCU, and a temperature sensor, to broadcast the ambient temperature through the light. The MCU is a Cortex M4 STM32F411. We configured the clock speed at just $8 \mathrm{MHz}$ using the hight speed external crystal oscillator. The board is powered by

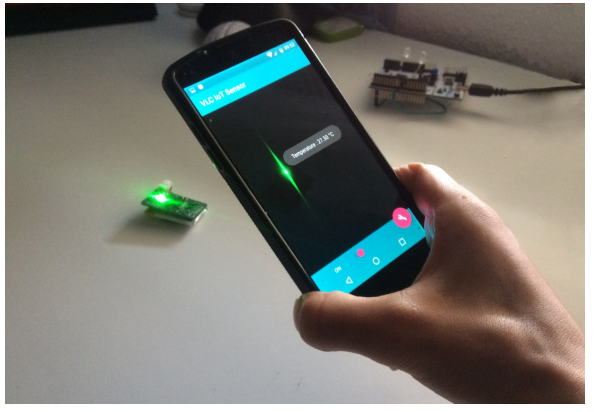

Figure 1: Aiming the VLC board with his smartphone, the user is getting the ambient temperature

a rechargeable $3.7 \mathrm{~V}$ polymer lithium battery. The firmware we developed polls periodically the DS18B20 temperature sensor, while it drives the LED to transmit the Manchester encoded data with On Off Keying modulation.

\subsection{Receiver}

On the receiver side, we use a LG Nexus 5 smartphone running Android Marshmallow version number 6.0.1. Its 8 megapixels CMOS sensor can capture up to to 30 frames per second and supports advanced imaging application provided by the Camera2 API.

We made an Android application that processes the picture on the background and displays the transmitted information in real time. To not put on the screen the dark and striped picture, captures are made in burst mode: the first frame, taken with regular parameters, is displayed in the app, while the other one, taken with a short exposure time, is sent to the background thread to be processed to decode the information.

In this way, by moving his smartphone, the user can see the ambient temperature in a popup that follows the LED on the screen, in an augmented reality fashion.

\section{CONCLUSIONS}

This demonstration proposes a comprehensive VLC application for the IoT by using a low-cost, low-power colored LED and an on-the-shelf smartphone. This work aims to spotlight the VLC technology as a great opportunity for smart and connected consumer electronics products. 